\title{
Erythromycin effects on gastric emptying, antral motility and plasma motilin and pancreatic polypeptide concentrations in anorexia nervosa
}

G Stacher, T L Peeters, H Bergmann, S Wiesnagrotzki, C Schneider, G V Granser-Vacariu, G Gaupmann, A Kugi

\begin{abstract}
In primary anorexia nervosa, gastric motility is often impaired and ensuing symptoms further discourage eating. Prokinetic agents have been shown to accelerate gastric emptying in affected patients. This study investigated whether emptying of a radiolabelled semisolid $1168 \mathrm{~kJ}$ meal and antral contractility were enhanced by intravenous erythromycin. Eight women and two men with anorexia nervosa (21-46 years, $50-75 \%$ of ideal body weight) received $200 \mathrm{mg}$ erythromycin or placebo under crossover double blind conditions. Gastric emptying and antral contractility were recorded scintigraphically for 90 minutes. In addition, plasma motilin and pancreatic polypeptide concentrations were determined. With placebo, antral contractions were of regular 3 cycles/minute frequency. With erythromycin, less frequent and partly arhythmic long duration contractions set in and emptying was accelerated: after 90 minutes, the activity remaining in the stomach was markedly less than with placebo in all patients (Sign test, $p<0.002)$. Basal motilin and pancreatic polypeptide concentrations were normal and showed a normal response to the meal in all patients. Motilin concentrations decreased slightly more and pancreatic polypeptide concentrations increased markedly more with erythromycin than with placebo, possibly because the meal reached the intestine earlier. In conclusion, erythromycin accelerated emptying markedly and in most patients induced an antral motor activity characterised by long duration contractions occurring at often irregular intervals.

(Gut 1993; 34: 166-172)
\end{abstract}

Medicine, Department of
Medision of Nuclear

Medicine II

H Bergmann

A Kugi

Division of

Psychosomatic

Medicine, Department of

Psychiatry

S Wiesnagrotzki

Gut Hormone

Laboratory, Department of Medical Research, Catholic University of

Leuven, Leuven,

Belgium

T L Peeters

Correspondence to:

Professor Dr G Stacher,

Psychophysiology Unit,

Währinger Gürtel 18-20,

A-1090 Wien, Austria

Accepted for publication

14 July 1992 antrum and the proximal duodenum, ${ }^{8}$ erythromycin and its derivatives may constitute a new group of agents, which could be of therapeutic value in patients with disordered gastroduodenal motor function. This is suggested also by preliminary results of studies in, albeit small, numbers of patients with such disorders. In abstract form, it has been reported that erythromycin enhanced gastric evacuation in 'many' of eight patients with delayed emptying after vagotomy and antrectomy ${ }^{9}$ and in four of five individuals with idiopathic or diabetic gastroparesis. ${ }^{10}$ The results of a study published in full showed that, in patients with diabetic gastroparesis, erythromycin accelerated gastric emptying not only when administered as a single intravenous dose, but also when given orally over a four week period. ${ }^{11}$

The aim of the present study was to evaluate the effects of erythromycin on the impaired gastric motor function shown to prevail in patients with primary anorexia nervosa. ${ }^{12-17}$ In such patients, in whom the resumption of normal eating behaviour often is discouraged by the symptoms of gastric stasis, an acceleration of gastric emptying by erythromycin not only would provide further information on the potential prokinetic properties of the compound, but also be of major clinical importance. In addition, the study was aimed at evaluating the effects of erythromycin on the plasma concentrations of motilin and pancreatic polypeptide.

\section{Methods}

\section{PATIENTS}

Eight female and two male patients meeting the diagnostic criteria for primary anorexia nervosa as defined by DSM III- ${ }^{18}$ and having been admitted for treatment at the Division of Psychosomatic Medicine of the Department of Psychiatry, University of Vienna, participated in the study. Their age ranged from 21 to 46 years (median, 24), their percentage of ideal body weight from $50 \cdot 1$ to $74.9 \%$ (median, $59 \cdot 7 \%$ ). None of them suffered from other diseases or took any drugs at the time of the investigation. The patients were given a short explanation of the purpose of the research and a description of the procedures to be followed. They further received a description of any reasonably foreseeable risks or discomforts. Written consent was obtained from each patient. The study was conducted in accordance with the provisions of the Declaration of Helsinki and its Tokyo Amendments. Before its initiation, the investiga- 
tion had been approved by the Institutional Committee on Studies Involving Human Beings.

PROCEDURE

Each patient participated in two study sessions four days apart, in which the effects of $200 \mathrm{mg}$ erythromycin (erythromycin lactobionate, Abbott, North Chicago, IL) administered by intravenous infusion on gastric emptying were compared with those of placebo under crossover double blind conditions. The patients were instructed to have their usual meal on the evenings preceding the study days but to refrain from eating after 2200 hours and not to eat or drink before coming to the laboratory at 0800 hours on the study days.

On their arrival at the laboratory, an indwelling catheter was inserted into a forearm vein and blood was drawn for the determination of basal plasma motilin and pancreatic polypeptide concentrations. Immediately thereafter, patients ingested a semisolid standard meal (for description see below), upon the completion of which another blood sample was taken. The patients now were seated between the two heads of a dual headed gamma camera and the intravenous infusion of $200 \mathrm{mg}$ erythromycin dissolved in $50 \mathrm{ml} 0.15 \mathrm{M}$ saline or of $50 \mathrm{ml} 0 \cdot 15 \mathrm{M}$ saline only (placebo) was started and continued over a 20 minute period using a motor pump (Unita I, Braun, Melsungen, Germany). At the same time as the infusion, the scintigraphic recording of gastric emptying commenced, which was carried out for 90 minutes. Further blood samples were taken at $20,30,45,60$, and 90 minutes after the start of infusin.

\section{MEASUREMENT OF GASTRIC EMPTYING AND} ANTRAL CONTRACTILE ACTIVITY

Gastric emptying was recorded by means of an isotope technique. ${ }^{16}{ }^{19} \mathrm{~A}$ semisolid test meal was labelled with a dose of $37 \mathrm{MBq}{ }^{99 m} \mathrm{Tc}$-sulphur colloid diluted in $0.15 \mathrm{M}$ saline. The adherance of the radiolabel to the test meal has been found to be reliable in previous in vitro experiments. ${ }^{16}$ The ingredients of the meal, which had a caloric content of 1168 kilo Joule and an osmolality of $558 \mathrm{mmol} / \mathrm{kg}$, were $250 \mathrm{ml}$ milk $(8.75 \mathrm{~g}$ protein, $8.75 \mathrm{~g}$ fat, $12.5 \mathrm{~g}$ carbohydrates), $15 \mathrm{~g}$ sugar, $14 \mathrm{~g}$ maize starch (Maizena ${ }^{\circledR}$, Knorr, Wels, Austria; $11.9 \mathrm{~g}$ carbohydrates) and, for flavouring, cinnamon. The meal was cooked slowly under continuous stirring until a semisolid consistency was reached. After cooling it to a temperature at which it could be ingested, it was mixed thoroughly with the radioisotope. The patients ate the test meal with a spoon.

Throughout the recording period, the patients sat in an armchair tilted at an angle of $60^{\circ}$ backwards to avoid possible overprojection of the stomach and the small intestine. A dual headed gamma scintillation camera (Rota-Camera, Siemens AG, Erlangen, Germany) fitted with $140 \mathrm{keV}$ parallel-hole collimators and interfaced to a computer system (System GAMMA-11, Digital Equipment Corporation, Marlboro, MA, USA) was used, with one camera head in an anterior and the other in a posterior position. The patient was positioned in such a way that the stomach appeared in the centres of the fields of view of the camera heads. Geometric means of anterior and posterior camera counts were calculated to correct for changing gamma ray attenuation by the subjects' tissues resulting from the movement of the labelled meal from the fundus to the antrum and from or towards the detectors. ${ }^{20}$ Data were also corrected for radionuclide decay.

Serial images of one minute frame time were acquired throughout the observation period except for minutes nine and 10,49 , and 50 as well as 89 and 90 after the start of recording, during which frame time was decreased to three seconds (s). The one minute frames were used to generate gastric emptying curves from a region of interest drawn visually around the stomach on the computer display. From these curves, background activity as counted in a region of interest drawn to the right of the gastric fundus and cranially of the antrum was subtracted, so that a falling count rate represented gastric emptying. The mean counts at each time were related to the counts at the start of recording, which were taken as $100 \%$. In addition, the half emptying time $t 1 / 2$ was calculated from the regression line of the count rate plotted on a logarithmic scale against time on a linear scale.

On the basis of the three second frames, antral motility was evaluated employing a factor analytic method. ${ }^{21}{ }^{22}$ Using principal component analysis and varimax rotation, this method at first identifies orthogonal factors. A subsequent oblique transformation of the factors ${ }^{23}$ makes use of the fact that, within the area imaged by the gamma camera, regions can always be identified, in which no temporal changes of radioactivity occur. These regions are utilised as a baseline setting and permit the computation of the transformation matrix, which then is applied to the varimax factors. The results of the transformation are expressed as factor images and factor curves, the latter essentially reflecting the factor loadings. Factor images and factor curves represent the activity changes recorded over the antrum and thereby the underlying contractile activity. Each of the factor images delineates an area of uniform activity change, wherein the relative intensity in each pixel represents the contribution of that element to the total activity change. The associated factor curves depict the global variation of intensities over time. Appropriately scaled, the factor curves correspond closely to activity time curves generated for regions of interest drawn over the prominent areas of the factor images. ${ }^{24}$

All computational work was done on a graphical work station (SparcStation IPC, Sun Microsystems, Mountain View, CA, USA). The software package Analyze ${ }^{25}$ was used for the display of the scintigraphic images, and a version of a program package for factor analysis implemented in the programming language $\mathrm{C}++$ (ToddPokropek A and Samal M, unpublished work) for the factor analysis. As an input, the latter program requires, apart from the image sequence to be analysed, the region in which the moving structures are to be identified - that is, a region corresponding to the anatomical bounds of the 
antrum, and a background region as described above. The analysis was set to account for three factors, since previous studies have shown that three factors explain more than $95 \%$ of the total variance of a given study of antral motility. As a measure of the amplitude of antral contractions, the mean modulation depth of each factor curve was derived from the standard deviation of the mean excursion of the individual points on the curve. ${ }^{16}{ }^{19}$ Then the autocorrelation function of the curve was computed and used to determine the frequency of antral contractions.

The total body radiation burden $(0 \cdot 1 \mathrm{mSv})$ resulting from one administered dose of the radionuclide as well as the dose absorbed by the stomach $(1.2 \mathrm{mSv})$ were less than the radiation burden arising from a single abdominal radiograph and therefore could be regarded as acceptable for the two consecutive studies carried out in the present investigation. ${ }^{26} 27$

DETERMINATION OF PLASMA MOTILIN AND PANCREATIC POLYPEPTIDE CONCENTRATIONS At the time points specified above, blood samples of $8 \mathrm{ml}$ each were drawn from a vein on the patients' forearm for the determination of plasma concentrations of motilin and pancreatic polypeptide. Blood was collected in tubes containing an appropriate amount of ethylenediamine tetra acetic acid. Fifty microlitres of aprotinin (Trasylol ${ }^{\circledR}$, Bayer, Leverkusen, Germany; $100000 \mathrm{KIU}$ in $10 \mathrm{ml}$ ) per $\mathrm{ml}$ of blood were added and plasma separated by centrifugation. The plasma then was frozen and stored at $-20^{\circ} \mathrm{C}$ until assayed.

Plasma concentrations of the two peptides were measured by radioimmunoassay as described previously. ${ }^{2829}$ The antiserum against motilin (antiserum 106) was raised in rabbits. It is specific for motilin's $\mathrm{N}$-terminus and does not cross react with other known regulatory peptides. For labelling and as a standard, porcine 13-norleucinmotilin was obtained from Novabiochem (Läufelfingen, Switzerland). The pancreatic polypeptide antibody, porcine pancreatic polypeptide for labelling and human pancreatic polypeptide as a standard were a gift from Dr E G Chance (Eli Lilly Company, Indianapolis, IN, USA). The smallest concentrations that could be distinguished with $95 \%$ confidence from zero were $4 \mathrm{pg} / \mathrm{ml}$ of motilin and $16 \mathrm{pg} / \mathrm{ml}$ of pancreatic polypeptide.

\section{ASSESSMENT OF ADVERSE EVENTS}

Unusual feelings as reported spontaneously by the patients were recorded along with the investigators' observations.

\section{STATISTICAL ANALYSIS}

The percentages of marker remaining in the stomach, the amplitude and the frequency of antral contractions as well as the plasma concentrations of motilin and pancreatic polypeptide were subjected to analyses of variance for repeated measures. ${ }^{30}$ The influences of the fixed factors 'treatment' (erythromycin, placebo), 'study day' $(1,2)$, 'time' (the 18 five minute periods of

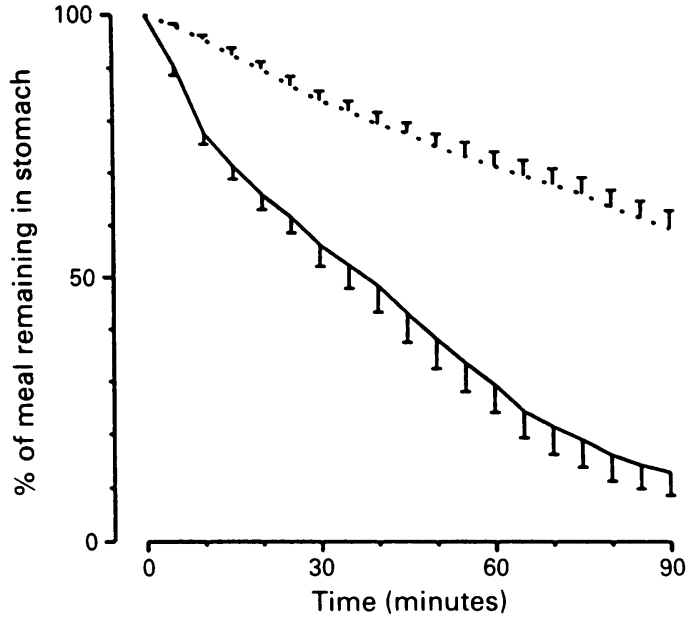

Figure 1: Gastric emptying of the semisolid test meal. Mean percentage of marker (SEM) remaining in the stomach over the 90 min after the start of the intravenous infusion of placebo $(. .$.$) ) and erythromycin (-)$, respectively.

recording of gastric emptying, the three periods of recording of antral motility and the seven time points at which blood samples were collected, respectively)and of the random factor 'patients' 1 to 10 ) were studied. As $t 1 / 2$ values usually are not normally distributed, these data were analysed using a non-parametric test - that is, the Wilcoxon's signed-rank test. ${ }^{31}$

\section{Results}

The analyses revealed that the sequence in which the patients received the two treatments in the two recording sessions had no significant influence on the variables measured.

\section{GASTRIC EMPTYING}

Percentage of marker remaining in the stomach

The emptying curves over time followed closely a monoexponential pattern under both experimental conditions(Fig 1). With placebo, the emptying rates were in the same range as the ones previously observed in our laboratory in patients with primary anorexia nervosa. ${ }^{11} 1216$ With erythromycin, emptying was markedly faster than with placebo in all of the patients. Whereas the percentages of meal remaining in the stomach at the end of the 90 minute recording period ranged from 40.6 to $72.5 \%$ (median, $60.9 \%$ ) after the infusion of placebo, they ranged from only 0.4 to $37 \cdot 1 \%$ (median, $4 \cdot 5 \%$ ) after erythromycin. The analysis of variance revealed that the effects of the two treatments differed highly significant $(F(1,9)=104 \cdot 34, \mathrm{p}<0.001)$.

\section{GASTRIC HALF EMPTYING TIME}

After the infusion of placebo, $t 1 / 2 \mathrm{~s}(70 \cdot 9-211 \cdot 1$ minutes; median, 136.7) of all patients were longer than the 75th percentile of $t 1 / 2 \mathrm{~s}$ of 48 healthy subjects studied in our laboratory using the same recording technique and the same standard meal (range of $\mathrm{t} 1 / 2 \mathrm{~s}, 21 \cdot 2-206 \cdot 0$ minutes, interquartile range, 41.9-64.0). After erythromycin, $\mathrm{t} 1 / 2 \mathrm{~s}(12 \cdot 5-94 \cdot 3$ minutes; median, $37 \cdot 2$ ) were markedly shorter than after placebo 


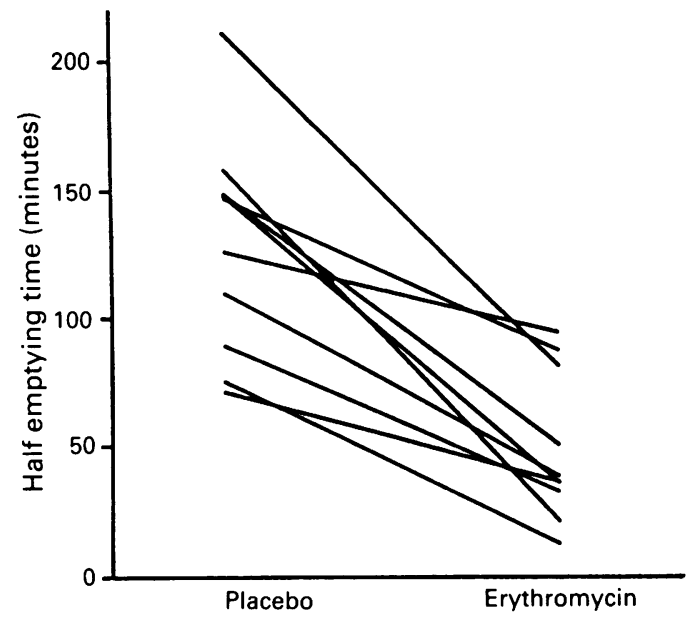

Figure 2: Gastric half emptying time. Half emptying times (in minutes) of the test meal after infusion of placebo and erythromycin, respectively, in the 10 individual patients.

infusion in all patients (Signed-rank test, $\mathrm{p}<0.002$; Fig 2). The $\mathrm{t} 1 / 2 \mathrm{~s}$ of six of the ten patients were even shorter than the 25 th percentile of the $t 1 / 2 \mathrm{~s}$ recorded in the 48 healthy subjects mentioned above.

\section{ANTRAL MOTOR ACTIVITY}

In the recording period nine to 10 minutes after the end of meal ingestion, all patients exhibited a rhythmic contractile antral activity at a mean frequency of $3 \cdot 27$ cycles $/ \mathrm{min}(0 \cdot 10)(\mathrm{SEM})$ when
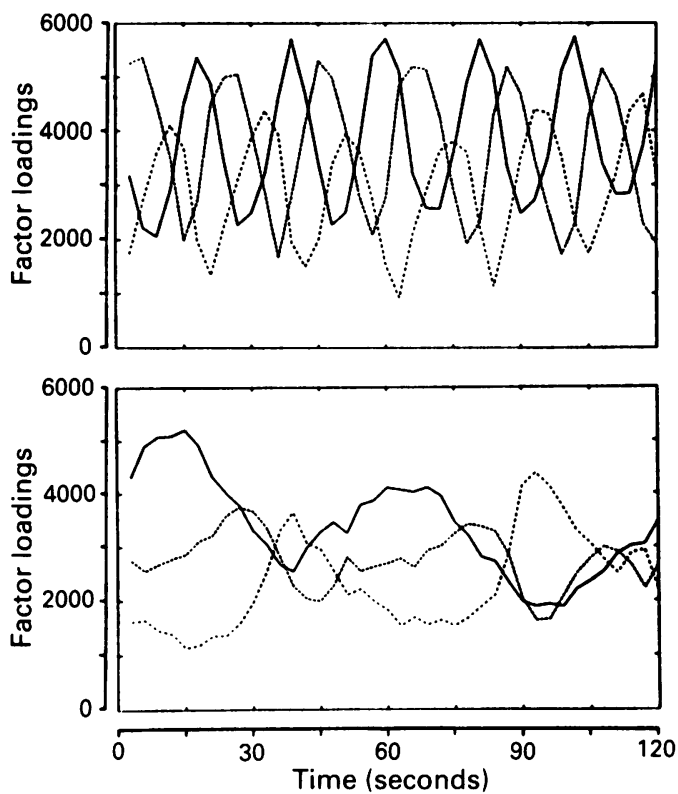

Figure 3: Antral motor activity as depicted by three factor curves (full, broken, and dotted lines). The factor curves represent the global variations of intensity over time in three factor images - that is, areas of uniform changes of radioactivity and thereby contractile activity, along the axis of the antrum. Corresponding to the differing contraction states in the areas of the respective factor images, the factor curves are shifted in time. Upper tracing. Factor curves in minutes nine and 10 after the start of infusion of placebo in patient CP. The curves reflect rhythmic contractions occurring at a mean frequency of 2.9 cycles/minute at three points along the axis of the antrum. Lower tracing. Factor curves in minutes nine and 10 after the start of infusion of erythromycin in patient CP. Note the less rhythmic antral motor activity and the long duration of the contractions at the three points along the axis of the antrum. placebo was infused. During erythromycin infusion, contractions occurred at a regular frequency of about three cycles/min in three patients but at less regular frequencies of $1 \cdot 13$ to 2.52 cycles/min in the remaining seven (Fig 3). Overall, the dominant frequency during erythromycin infusion $(2.34(0.24)$ cycles $/ \mathrm{min})$ was significantly lower $(F \quad(1,9)=10 \cdot 10$, $\mathrm{p}<0.02$ ) than during placebo infusion. The mean amplitude of contractions during the infusion of erythromycin (7.9\% modulation depth $(1 \cdot 2))$ differed only little from the mean amplitude during placebo infusion $(7 \cdot 5(0 \cdot 7) \%)$, whereas the maximal amplitudes were markedly higher with erythromycin $(16.2(4.3) \%)$ than with placebo $(9 \cdot 1(0 \cdot 9) \% ; F(1,9)=3 \cdot 37, \mathrm{p}<0 \cdot 1)$.

In the recording period 49-50 minutes after meal ingestion, antral contraction frequency remained stable when placebo had been infused $(3.27(0.23)$ cycles/min) and mean as well as maximal amplitudes were lower than in the first recording period $(4.7(0.5) \%$ and $4.8(0.8) \%$, respectively). After erythromycin, the partly arhythmic pattern of contractile activity persisted; the amplitude of contractions could not reliably be quantitated any more, as the radioactivity remaining in the stomach at that time point was insufficient for these measurements in seven of the 10 patients. In the $89-90 \mathrm{~min}$ recording period, frequency as well as mean and maximal amplitude of contractions showed no changes from the values observed in the 49-50 minute period when placebo had been administered $(3.30(0 \cdot 22)$ cycles/min, $4 \cdot 7(0.9) \%$ and $5 \cdot 4$ $(0.9) \%$, respectively). When erythromycin had been infused, the contractile activity could be recorded in only one patient, because there was too little radioactivity left in the antrum of the remaining nine.

PLASMA CONCENTRATIONS OF MOTILIN AND PANCREATIC POLYPEPTIDE

Motilin and pancreatic polypeptide concentrations could be determined in all studies with erythromycin administration but, because of

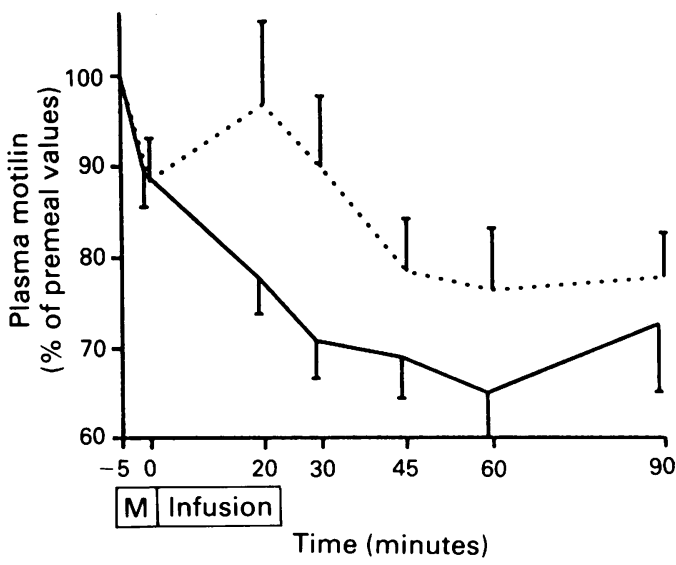

Figure 4: Plasma motilin concentrations. Mean motilin concentrations (SEM) in percent of values measured before $(-5 \mathrm{~min})$ the ingestion of the standard meal $(M)$, after meal ingestion and anteceding the start of infusion of erythromycin or placebo $(0$ min), as well as $20,30,45,60$, and 90 minutes thereafter. Placebo studies $(. .$.$) , erythromycin studies$ (-). 
unsurmountable difficulties in obtaining blood from the emaciated patients' veins, in only eight of the 10 with placebo infusion.

Basal motilin concentrations ranged from 246 to $783 \mathrm{pg} / \mathrm{ml}$ (mean, $447.9 \mathrm{pg} / \mathrm{ml}(67.9)$ (SEM) before placebo administration and from 229 to $665 \mathrm{pg} / \mathrm{ml}$ (mean, $410.9(57.8) \mathrm{pg} / \mathrm{ml}$ ) before erythromycin. In all cases, motilin levels decreased gradually over the first 60 minutes after the start of the infusion. In the patients in whom motilin could be determined with both treatments, plasma concentrations decreased, on the mean, faster and more with erythromycin than with placebo (Fig 4). The analysis showed that the effects of the two treatments differed statistically $(F(1,7)=11 \cdot 5, \mathrm{p}<0 \cdot 02)$. The overall downwards trend of plasma concentrations resulted in a significant $F$ value for the time factor $(F(6,42)=10.56, \quad \mathrm{p}<0.001)$. At 90 minutes, motilin levels were slightly higher than at 60 minutes in seven of the 10 patients having received erythromycin and in four of the eight patients, in whom motilin concentrations could be measured after placebo administraton.

Basal pancreatic polypeptide concentrations ranged from $29 \mathrm{pg} / \mathrm{ml}$ to $489 \mathrm{pg} / \mathrm{ml}$ (mean, 198.9 $(54.4) \mathrm{pg} / \mathrm{ml}$ ) before placebo administration and from $30 \mathrm{pg} / \mathrm{ml}$ to $382 \mathrm{pg} / \mathrm{ml}$ (mean, 152.5 (24.7) $\mathrm{pg} / \mathrm{ml}$ ) before infusion of erythromycin. In all patients, pancreatic polypeptide concentrations increased sharply with meal ingestion, the increases being about as high in the patients in whom subsequently erythromycin was infused as in the ones who subsequently received placebo (Fig 5). Immediately after placebo infusion, plasma concentrations were only slightly higher than before and peak levels occurred either at that time point or 10 minutes later. After the infusion of erythromycin, however, plasma concentrations were markedly higher than before the infusion in all of the patients (Fig 5). Thereafter, pancreatic polypeptide concentrations decreased again but remained on a higher level than after placebo throughout the recording time. The analysis showed that the treatment effects differed, although statistical significance was not

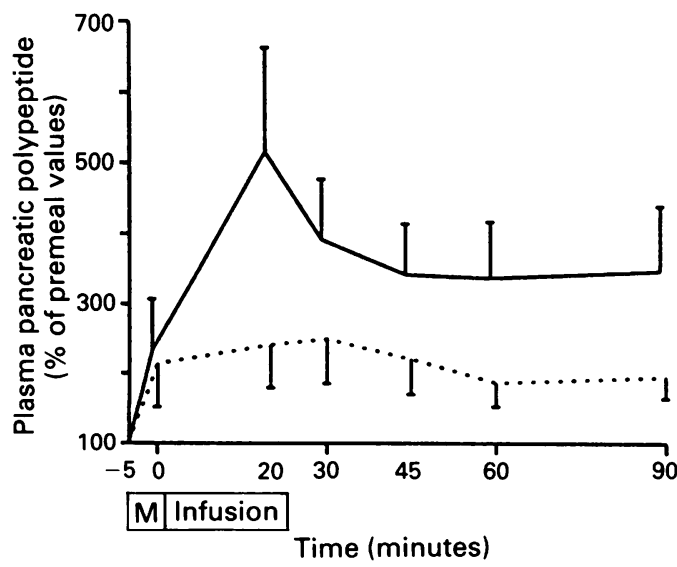

Figure 5: Plasma pancreatic polypeptide concentrations. Mean pancreatic polypeptide concentrations $(S E M)$ in percent of values measured before $(-5 \mathrm{~min})$ the ingestion of the standard meal $(M)$, after meal ingestion and anteceding the start of infusion of erythromycin or placebo $(0 \mathrm{~min})$, as well as 20,30,45, 60, and 90 minutes thereafter. Placebo studies $(\cdots)$, erythromycin studies $(-)$. reached $(F(1,7)=3 \cdot 78, \mathrm{p}<0 \cdot 1)$. The overall upwards trend after meal ingestion was reflected by a significant $F$ value for the influence of the time factor $(F(6,42)=6.33, \mathrm{p}<0.001)$ and the differing treatment effects over time by a significant $F$ value for the interaction treatment $v$ time $(F(6,42)=2.93, \mathrm{p}<0.02)$.

\section{ADVERSE EFFECTS}

Twenty and 25 minutes after the start of the infusion of erythromycin, respectively, two of the 10 patients reported slight nausea which lasted for about five minutes. More intense but still moderate nausea was reported by another patient at 15 minutes after the start of infusion. In this patient, as well, the feeling subsided after five minutes. In one patient, the investigators noted abdominal rumbling in the period 15 to 25 minutes after the start of erythromycin administration. No adverse events whatsoever were reported or observed during and after placebo infusion.

\section{Discussion}

The results of the present study show that erythromycin markedly accelerated gastric emptying in all of the 10 patients with primary anorexia nervosa studied. This finding is consistent with observations made in patients with diabetic $^{1011}$ and idiopathic gastroparesis, ${ }^{10}$ and with impaired gastric motor function after vagotomy and antrectomy. ${ }^{9}$ Erythromycin markedly accelerated the delayed gastric emptying not only in relation to the emptying rate prevailing with placebo, but to such an extent that, in six of the 10 patients, $t 1 / 2 \mathrm{~s}$ were shorter than the 25 th percentile of the $t / 2 \mathrm{~s}$ recorded in a group of 48 healthy individuals using the same recording technique and the same standard meal. A similar observation has been made by Janssens et $a^{11}$ : in patients with diabetic gastroparesis having received erythromycin, the emptying of solid meal constituents was more rapid than in healthy untreated volunteers.

The enhanced emptying during and after erythromycin administration was associated, in the period nine to 10 minutes from the end of meal ingestion, with strong antral contractions of long duration. In contrast with the entirely rhythmic antral activity occurring at a frequency of about three cycles/minute during and after the infusion of placebo, these contractions were of lower and often irregular frequency. The induction by intravenous erythromycin of forceful antral contractions has also been reported by other authors, who had observed this phenomenon to occur not only in the postprandial period ${ }^{3233}$ but also in the interdigestive state. ${ }^{33-36}$ That these contractions often do not take place at the regular rate of about three cycles/minute, characteristic for the antrum after a meal, but much less frequently, has been reported earlier as well: in 13 fasted healthy subjects, erythromycin induced powerful peristaltic contractions with a mean occurrence of 0.96 per minute and, in eight fasted patients with diabetic gastroparesis, with a mean occurrence of 0.52 per minute. ${ }^{36}$ Eight healthy men exhibited antral contractions of 
large amplitude and long duration setting in six to nine minutes after the start of erythromycin infusion, which occurred at a mean frequency of about 2.4 cycles/minute in the fasting state and at a mean frequency of about $2 \cdot 0$ cycles/minute in the fed state. ${ }^{33}$ No erythromycin induced arhythmias have been detected in studies recording the electrogastrogram from electrodes attached to the skin of the abdomen. In 10 lightly sedated cynomolgus monkeys, erythromycin increased the amplitude and decreased the frequency of the signal, which remained rhythmic. ${ }^{37}$ It has even been reported that, in four patients with gastroparesis, erythromycin converted electrogastrographically recorded arhythmic slow waves into regularly occurring waves. ${ }^{38}$ The discrepancy between these reports and the findings of the present as well as of a previous study ${ }^{36}$ possibly is because the cutaneously recorded electrogastrogram reflects the slow wave activity only and not the superimposed spiking activity and thus can give no, and be it indirect, information on the contractions of the antrum.

Whether the accelerating effect of erythromycin on gastric emptying has to be attributed primarily to the induction of forceful antral contractions or to an effect on gastric tone, cannot be answered from the results of the present study. The strength of antral contractions, however, seems to play an important role. In healthy subjects, the emptying of solid, but not of liquid, meal constituents has been found to be slow with low antral motor activity and faster with a more active antrum. ${ }^{39}$ Similarly, in patients with gastric stasis, a slow emptying rate for solids was found to be associated with antral hypomotility. ${ }^{40}$ In a previous study in which the effects of the gastroprokinetic agent, cisapride, were evaluated in patients with primary anorexia nervosa and in which the same semisolid meal and the same recording technique was used as in the present investigation, the rate of emptying was related significantly to the amplitude of antral contractions. ${ }^{16}$

The fall in motilin concentrations under both experimental conditions could be related mainly to an increase in blood glucose levels, as it has been reported $^{41}$ that plasma motilin declined significantly after both the ingestion and the intravenous infusion of glucose. Such a mechanism would explain the fact that the plasma concentrations of motilin decreased more and earlier when erythromycin was administered: in this condition gastric emptying was faster than with placebo thus enabling an earlier absorption of the meal constituents in the small intestine. A direct effect of erythromycin on plasma motilin levels cannot be ruled out although it has been observed that erythromycin had no such effect in fasting humans. ${ }^{2}$ In fasted dogs, erythromycin induced a motilin release. ${ }^{1}$

Plasma pancreatic polypeptide concentrations under basal conditions were within the normal range in all patients and in all experimental sessions and also exhibited the normally occurring sharp increase after meal intake. In an earlier study in patients with anorexia nervosa, ${ }^{42}$ the pancreatic polypeptide response to the meal did not differ from the one observed in healthy control subjects and in another it was only slightly more accentuated..$^{43}$ Uhe et $a l^{44}$ observed a significantly greater postprandial pancreatic polypeptide increase to occur in anorectic patients; this, together with the fact that low basal pancreatic polypeptide concentrations have been reported to prevail in obese subjects, ${ }^{45}$ led them to suggest that pancreatic polypeptide might play a role in the regulation of appetite and food intake. As the control of pancreatic polypeptide release is thought to be largely under vagal cholinergic control, ${ }^{467}$ they also hypothesised that the more accentuated pancreatic polypeptide response might be the result of a high vagal drive. ${ }^{44}$ Their data do not look very convincing, however, as the postprandial pancreatic polypeptide concentrations in their patients with anorexia show great variation, whereas those of their six healthy control subjects vary very little. Moreover, a high vagal drive should also lead to increased basal pancreatic polypeptide concentrations, a feature which was present neither in the patients of Uhe et $\mathrm{al}^{44}$ nor in those of the present investigation. Further and more prolonged studies in the pancreatic polypeptide response of patients with anorexia nervosa to a meal are needed to clarify this matter. After the infusion of erythromycin, the levels of pancreatic polypeptide were much higher than after placebo infusion. This seems to be because of the acceleration of gastric emptying produced by erythromycin and the consecutive earlier onset of the intestinal phase of pancreatic polypeptide release. ${ }^{48} \mathrm{~A}$ pronounced rise in pancreatic polypeptide concentrations has been observed to be associated also with a motilin induced enhancement of gastric emptying in patients with diabetic gastroparesis, ${ }^{49}$ although in these patients the normally occurring early rise in pancreatic polypeptide, which is thought to result from stimuli transmitted through the vagal nerves ${ }^{48}$ failed to take place, probably as a result of autonomic neuropathy..$^{50}$

Adverse effects of erythromycin as observed in the present study - that is, slight to moderate nausea in three of the 10 patients and borborhygmi in one, have been reported to occur also by other workers. ${ }^{32}{ }^{33}$ The fact that the incidence of side effects was somewhat higher in the latter studies may be because the doses administered were, on a mg per kg body weight basis, at least twice as high than the dose administered in the present investigation. The same explanation might apply to the fact that $200 \mathrm{mg}$ of erythromycin intravenously induced side effects in the present study but not in patients with diabetic gastroparesis ${ }^{11}$ : the latter may have received a lower dose on a mg per $\mathrm{kg}$ basis as their body weights, presumably, were in the normal range, whereas our patients had a median weight of only $59 \cdot 7 \%$ of their ideal body weight.

In conclusion, erythromycin, $200 \mathrm{mg}$ administered by slow intravenous infusion, markedly accelerated the slow gastric emptying of a semisolid meal in all of the 10 primary anorexia nervosa patients studied and, in seven of them, changed the entirely rhythmic antral motor activity in the immediate postprandial period into one characterised by stronger and longer lasting contractions occurring at a lower rate and at often irregular intervals. These results further 
add to the evidence that erythromycin is endowed with potent gastroprokinetic properties and that related compounds, devoid of antibiotic activity, may represent promising tools in the future treatment of impaired gastric motor function in a variety of conditions.

Presented in part at the 13th International Symposium on Gastroíntestinal Motility, 17-21 November 1991, Kobe, Japan, and published in abstract form in the $\mathcal{F}$ Gastrointest Motility 1991 ; 3: 201 .

1 Itoh Z, Nakaya M, Suzuki T, Arai H, Wakabayashi K. Erythromycin mimics exogenous motilin in gastrointestinal contractile activity in the dog. Am $\mathcal{F}$ Physiol 1984; 247: G688-94.

2 Tomomasa T, Kuroume T, Arai H, Wakabayashi K, Itoh Z. Erythromycin induces migrating motor complex in human gastrointestinal tract. Dig Dis Sci 1986; 31: 157-61.

3 Peeters TL, Matthijs G, Depoortere I, Cachet T, Hoogmartens J, Vantrappen G. Erythromycin is a motilin receptor agonist. Am F Physiol 1989; 257: G469-74.

4 Depoortere I, Peeters TL, Vantrappen G. The erythromycin derivative EM-523 is a potent motilin agonist in man and in rabbit. Peptides 1990; 11: 515-9.

5 Omura S, Tsuzuki K, Sunazuka T, Marui S, Toyoda $H$, Inatomi $\mathrm{N}$, et al. Macrolides with gastrointestinal motor stimulating activity. $\mathcal{F}$ Med Chem 1987; 30: 1941-3.

6 Peeters TL, Matthijs G, Vantrappen G. $\mathrm{Ca}^{2+}$ dependence of motilide-induced contractions in rabbit duodenal muscle strips in vitro. Naunyn Schmiedebergs Arch Pharmacol 1991; 343: 202-8.

7 Depoortere I, Peeters TL, Matthijs G, Cachet T, Hoogmartens J, Vantrappen G. Structure-activity relation of erythromycin-related macrolides in inducing contractions and in displacing bound motilin in rabbit duodenum. Fournal of Gastrointestinal Motility 1989; 1: 150-9.

8 Peeters TL, Bormans V, Vantrappen G. Comparison of motilin binding to crude homogenates of human and canine gastroin $171-82$.

9 Ramirez B, Sninsky CA, Drane WE, Eaker EY, Hocking MM. Does erythromycin enhance gastric emptying in patients with a vagotomy and antrectomy? [Abstract]. Gastroenterology 1990; 99: 1232.

10 Richards RD, Davenport KG, Hurm KD, Wimbish WR, McCallum RW. Acute and chronic treatment of gastroparesis with erythromycin [Abstract]. Gastroenterology 1990; 98: A385.

11 Janssens J, Peeters TL, Vantrappen G, Tack J, Urbain JL, De Roo M, et al. Improvement of gastric emptying in diabetic gastroparesis by erythromycin. Preliminary studies. diabetic gastroparesis by erythromycin

12 Dubois A, Gross HA, Ebert MH, Castell DO. Altered gastric emptying and secretion in primary anorexia nervosa. Gastro-

13 Holt S, Ford MJ, Grant S, Heading RC. Abnormal gastric emptying in primary anorexia nervosa. Br f Psychiatry 1981; 139: 550-2.

14 McCallum RW, Grill BB, Lange R, Planky M, Glass EE, Greenfeld DG. Definition of a gastric emptying abnormality in patients with anorexia nervosa. Dig Dis Sci 1985; 30: 71322 .

15 Stacher G, Kiss A, Wiesnagrotzki S, Bergmann H, Höbart J, Schneider C. Oesophageal and gastric motility disorders in patients categorised as having primary anorexia nervosa. Gut patients categorise

16 Stacher G, Bergmann H, Wiesnagrotzki S, Kiss A, Schneider C, Mittelbach G, et al. Intravenous cisapride accelerates delayed gastric emptying and increases antral contraction
amplitude in patients with primary anorexia nervosa. Gastroamplitude in patients with prim

17 Stacher G, Bergmann H, Wiesnagrotzki S, Steiner-Mittelbach G, Kiss A, Abatzi Th-A. Primary anorexia nervosa: gastric emptying and antral motor activity in 53 patients. International fournal of Eating Disorders 1992; 11: 163-72.

18 American Psychiatric Association. Diagnostic and statistical manual of mental disorders. 3rd ed. Revised. Washington, DC: American Psychiatric Association, 1987: 67-9.

19 Jacobs F, Akkermans LMA, Oei Hong Yoe, Hoekstra A, Wittebol P. A radioisotope method to quantify the function of fundus, antrum, and their contractile activity in gastric of fundus, antrum, and their contractile activity in gastric emptying of a semisolid meal. In: Wienbeck M, ed. Motility
of the digestive tract. New York: Raven Press, 1982: 233-40.

20 Christian PE, Moore JG, Sorenson JA, Coleman RE, Weich DM. Effects of meal size and correction technique on gastric emptying time: studies with two tracers and opposed detectors. F Nucl Med 1980; 21: 883-5.

21 Samal M, Karny M, Surova H, Marikova E, Dienstbier Z. Rotation to simple structure in factor analysis of dynamic radionuclide studies. Phys Med Biol 1987; 32: 371-82.

22 Barber DC. The use of principal components in the quantitative analysis of gamma camera dynamic studies. Phys Med Biol 1980; 25: 283-92.
23 Samal $M$, Karny $M$, Surova $H$, Penicka $P$, Maricova E, Dienstbier $Z$. On the existence of an unambiguous solution in factor analysis of dynamic studies. Phys Med Biol 1989; 34: 223-8.

24 Bergmann H, Stacher G, Mittelbach G, Höbart J, StacherJanotta G, Gaupmann G, et al. Measurement of gastric emptying and antral motor activity in patients with primary anorexia nervosa. Methodology and problems. In: Dynamic functional studies in nuclear medicine in developing countries. Proceedings of an International Symposium, Vienna, 15-19 Proceedings of an International Symposium, Vienna, 15-19
August 1988. Vienna International Atomic Energy Agency, August 1988.

25 Robb RA, Hanson DP, Karwoski RA, Larson AG, Workman EL, Stacy MC. ANALYZE: a comprehensive, operatorinteractive software package for multidimensional medical 433-54.

26 Siegel JA, Wu RK, Knight LC, Zelac RE, Stern HS, Malmud LS. Radiation dose estimates for oral agents used in upper gastrointestinal disease. $7 \mathrm{Nucl} \mathrm{Med} \mathrm{1983;24:} \mathrm{835-7.}$

27 Horowitz M, Collins PJ, Shearman DJC. Disorders of gastric emptying in humans and the use of radionuclide techniques. Arch Intern Med 1985; 145: 1468-72.

28 Peeters TL, Vantrappen G, Janssens J. Fasting plasma motilin levels are related to the interdigestive motility complex. levels are related to the interdised
Gastroenterology 1980; 79: 716-9.

29 Janssens J, Hellemans J, Adrian TE, Bloom SR, Peeters TL, Christofides N, et al. Pancreatic polypeptide is not involved in the regulation of the migratory motor complex in man. in the regulation of the mig
Regul Pept 1982; 3: 41-9.

30 Games PA. Computer programs for robust analyses in multifactor analysis of variance designs. Educ Psychol Measure 1975; 35: 147-52.

31 Conover WJ. Practical nonparametric statistics. New York: John Wiley, 1971.

32 Annese V, Janssens J, Vantrappen G, Willemse P, Peeters T. Erythromycin accelerates gastric emptying by the induction of power contractions in the gastric antrum [Abstract]. fournal of Gastrointestinal Motility 1989; 1: 46.

33 Sarna SK, Soergel KH, Koch TR, Stone JE, Wood CM, Ryan $\mathrm{RP}$, et al. Gastrointestinal motor effects of erythromycin in

humans. Gastroenterology 1991; 101: 1488-96.
34 Zara G-P. Qin XY, Pilot M-A, Thompson H, Maskell J. Response of the human gastrointestinal tract to erythromycin. Fournal of Gastrointestinal Motility 1991; 3: 26-31.

35 Otterson MF, Sarna SK. Motor patterns associated with the gastrointestinal side effects of erythromycin [Abstract]. Gastroenterology 1988; 95: 883.

36 Vantrappen G, Janssens J, Tack J, Muls E, Bouillon R, Peeters $T$. Erythromycin is a potent gastrokinetic in diabetic gastroparesis [Abstract]. Gastroenterology 1989; 95: A525.

37 Sinar DR, Joyce JM, Ellis SP. The prokinetic effect of erythromycin: gastric emptying correlated with electro-
gastrography [Abstract]. Gastroenterology 1990; 99: 1231 .

38 Chen J, McCallum RW, Davenport KG, Abbitt P. Erythromycin enhances the gastric slow wave in gastropareErythromycin enhances the gastric slow wave in gastropart

39 Camilleri M, Malagelada J-R, Brown ML, Becker G Zinsmeister AR. Relation between antral motility and gastric emptying of solids and liquids in humans. $\mathrm{Am} \mathcal{F}$ Physiol 1985; 249: G580-5.

40 Camilleri M, Brown ML, Malagelada J-R. Relationship between impaired gastric emptying and abnormal gastrointestinal motility. Gastroenterology 1986; 91: 94-9.

41 Christofides ND, Bloom SR, Besterman HS, Adrian TE, Ghatei MA. Release of motilin by oral and intravenous nutrients in man. Gut 1979; 20: 102-6.

42 Tovoli S, Bolelli GF, Patrono D, Severi D, Gasbarrini G. Release of pancreatic hormones in anorexia nervosa Release .of pancreatic hormones in
[Abstract]. Dig Dis Sci 1984; 29: A28.

43 Alderdice JT, Dinsmore WW, Buchanan KD, Adams C. Gastrointestinal hormones in anorexia nervosa. $\mathcal{F}$ Psychiatr Res 1985; 19: 207-13.

44 Uhe AM, Szmukler GI, Collier GR, Hansky J, O'Dea K, Young GP. Potential regulators of feeding behavior in anorexia nervosa. Am F Clin Nutr 1992; 55: 28-32.

45 Schmid R, Schusdziarra V, Schulte F, Maier V, Classen M. Circulating amino acids and pancreatic endocrine function after ingestion of a protein-rich meal in obese subjects. $\mathcal{F}$ Clin Endocrinol Metab 1989; 68: 1106-10.

46 Schwartz TW. Pancreatic polypeptide: a hormone under vagal control. Gastroenterology 1983; 85: 1411-25.

47 Monnikes M, Koop H, Ehlenz K, Dionysius J, Arnold R. Role of circulating catecholamines in the control of pancreatic polypeptide and gastrin release. Res Exp Med (Berl) 1989; polypeptide

48 Adrian TE, Bloom SR, Besterman HS, Barnes AJ, Cooke TJC, Russell RCG, et al. Mechanism of pancreatic polypeptide release in man. Lancet 1977; i: 161-3.

49 Peeters TL, Muls E, Janssens J, Urbain JL, Bex M, van Cutsem E, et al. Effect of motilin on gastric emptying in patients with diabetic gastroparesis. Gastroenterology 1992; 102: $97-101$

50 Gambardella S, Felici MG, Annibale B, Delle Fave GF, Jacoangeli F, Spallone V, et al. Pancreatic polypeptide response to a protein-rich meal in diabetic patients with and without neuropathy. $\mathcal{F}$ Endocrinol Invest 1986; 9: $1-4$. 